\section{FLT3/ITD associated with an immature immunophenotype in PML-RAR $\alpha$ leukemia}

\author{
Mariko Takenokuchi, ${ }^{1}$ Seiji Kawano, ${ }^{2}$ \\ Yuji Nakamachi, ${ }^{2}$ Yasuyuki Sakota, ${ }^{2}$ \\ Meilani Syampurnawati, ${ }^{3}$ \\ Katsuyasu Saigo, ${ }^{1}$ Eiji Tatsumi, ${ }^{4}$ \\ Shunichi Kumagai ${ }^{5}$ \\ 'Faculty of Pharmacological Sciences, \\ Himeji Dokkyo University, Himeji, Hyogo; \\ Japan; ${ }^{2}$ Department of Clinical \\ Laboratory, Kobe University Hospital, \\ Kobe, Hyogo, Japan; ${ }^{3}$ Department of \\ Internal Medicine, Faculty of Medicine, \\ Gadjah Mada University, Dr Sardjito \\ Hospital, Jalan Kesehatan, Yogyakarta, \\ Indonesia; ${ }^{4}$ Department of Nutrition \\ and Health, Sagami Women's University, \\ Sagami, Kanagawa, Japan; \\ ${ }^{5}$ Department of Clinical Pathology and \\ Immunology, Kobe University Graduate \\ School of Medicine, Kobe, Hyogo, Japan
}

\section{Abstract}

Acute promyelocytic leukemia (APL) is characterized by the specific PML-RAR $\alpha$ fusion gene resulting from translocation $\mathrm{t}(15 ; 17)$ (q22;q12). Internal tandem duplication (ITD) of the FLT3 gene has been observed in approximately $35 \%$ of APLs, and large-scale studies have identified the presence of ITD as an adverse prognostic factor for acute myeloblastic leukemia (AML) patients. Aberrant expressions of surface antigens, such as CD2, CD34, and CD56, have been found in APL, but the implications of this are not well understood. We investigated the incidence of the FLT3/ITD mutation and FLT3/D835 (I836) point mutation in $25 \mathrm{APL}$ patients. Incidence ratios of FLT3/ITD, D835 (I836), and both FLT3/ITD and D835 (I836) were $36 \%, 36 \%$ and $8 \%$, respectively. FLT3/TTD ${ }^{+}$cases showed a predominance of the bcr3 isoform ( $\mathrm{P}=0.008)$ and $\mathrm{M} 3 \mathrm{v}$ morphology $(\mathrm{P}<0.001)$. We found that all FLT3/ITD ${ }^{+}$cases expressed CD2 (9 of 9) more frequently than that of FLT3/TTD- (1 of 16) $(\mathrm{P}<0.001)$, while only one of the $\mathrm{CD} 2^{+}$cases $(1$ of 10,10\%) did not harbor FLT3/TTD, and all $\mathrm{CD} 2{ }^{+} \mathrm{CD} 4^{+}$cases $(5$ of $5,100 \%$ ) harbored FLT3/ITD. In addition, quantitative polymerase chain reaction analysis showed that FLT3 mRNA was more abundantly expressed in FLT3/ITD $^{+}$than that in FLT3/ITD ${ }^{-}(\mathrm{P}=0.025)$, while there was no difference between D835(I836) ${ }^{+}$and D835(I836) ${ }^{-}$with regards to aberrant surface-antigen expression, expres- sion levels of FLT3 mRNA, M3v morphology, and the bcr3 isoform of PML-RAR $\alpha$ mRNA. This study demonstrates that the presence of FLT3/ITD, but not D835 (I836), is closely related to aberrant CD2 expression and high expression levels of FLT3 mRNA. Our findings also suggest that FLT3/ITD as a secondary genetic event may block differentiation at the immature stage of APL.

\section{Introduction}

Acute promyelocytic leukemia (APL), characterized by the specific PML-RAR $\alpha$ fusion gene resulting from translocation $\mathrm{t}(15 ; 17)(\mathrm{q} 22 ; \mathrm{q} 12)$ and unique sensitivity to the differentiating effect of all-trans retinoic acid (ATRA), features three types of heterogeneity: clinical [white blood cell (WBC) counts, age, and treatment outcome ], morphological (hypergranular M3 and micro/ hypogranular M3v), and molecular (three isoforms of PML breakpoint). ${ }^{1,2}$ APL has also been the subject of immunophenotypic studies, which have yielded results that included positive staining for CD33, CD13, and CD19 antigens, an absence of HLA-DR expression, and low-frequency occurrence of CD7, CD11b, and CD14 expression. Aberrant surface antigens, including CD2 and CD34, have also been identified. $^{3,4}$ Although the clinical relevance of these surface antigens is not yet well understood, several research groups have demonstrated that the expression of CD2 is associated with micro/hypogranular M3v morphology and the bcr3 PML-RAR $\alpha$ isoform, and that of CD34 with an immature form of APL.,5-7 In addition, the presence of the neural cell adhesion molecule CD56 has been shown to be predictive of poor outcome in patients treated with ATRA in combination with chemotherapy. ${ }^{8}$ We also reported several cases that showed expression of HLA-DR or terminal deoxynucleotidyl transferase (TdT), which is usually negative in APL cases. ${ }^{9}$ The fms-like tyrosine kinase 3 (FLT3) gene, a newly discovered member of the Class III receptor tyrosine kinase (RTK) subfamily, was originally identified by its expression in hematopoietic stem/progenitor cells, and its importance in hematopoiesis has now been well established. ${ }^{10}$ FLT3 is aberrantly expressed in the majority of acute myeloblastic leukemias (AML). ${ }^{11}$ The most common molecular defect identified to date in AML is internal tandem duplication (ITD) in the juxtamembrane domain (JM) of the FLT3 gene (FLT3/ITD). Activating point mutations within the activation loop (ALM) of the tyrosine kinase domain 2 (TKD2) of FLT3, which are mainly located in D835, I836, Y842, or D853, have also been
Correspondence: Mariko Takenokuchi, Faculty of Pharmacological Science, Himeji Dokkyo University, 7-2-1 Kamiohno-cho, Himeji, Hyogo 670-8524, Japan. Tel/Fax: +81.79.2236853.

E-mail: tmariko@himeji-du.ac.jp

Acknowledgements: we are grateful to our colleagues in the clinical laboratory of Kobe University Hospital for their secretarial and technical assistance.

Key words: FLT3/TD, FLT3/ D835, CD2, immature phenotype.

Conflict of interests: the authors report no conflict of interests.

Received for publication: 27 June 2012.

Revision received: 25 September 2012.

Accepted for publication: 11 October 2012.

This work is licensed under a Creative Commons Attribution NonCommercial 3.0 License (CC BYNC 3.0).

(C) Copyright M. Takenokuchi et al., 2012 Licensee PAGEPress, Italy

Hematology Reports 2012; 4:e22

doi:10.4081/hr.2012.e22

reported for AML. FLT3/ITD or FLT3/D835 point mutations, which lead to constitutive activation of FLT3 tyrosine kinase, have been detected in $20-25 \%$ of AMLs, and notably in approximately $35 \%$ of APL. ${ }^{12-14}$ Large-scale studies have identified the presence of ITD as an adverse prognostic factor for pediatric and adult AML patients. ${ }^{12,13,15,16}$ More recently, some groups reported that FLT3/ITD is related to a high white blood count, M3v morphology, and the bcr3 PML-RAR $\alpha$ isoform, and that it clinically tends to indicate inferior overall survival for APL patients. ${ }^{17-19}$ These findings raise the possibility that APL with FLT3 gene mutations may constitute a distinct subset of APL.

In this study, we investigated the possible relationship between FLT3 gene status, including FLT3 mutations and FLT3 mRNA levels, and morphological, immunophenotypic, and molecular characteristics of 25 APL patients positive for PML-RAR $\alpha$ mRNA. We were able to show that there was a significant relationship between the presence of FLT3/TD and an immature immunophenotype characterized by the expression of an aberrant surface-antigen, CD2.

\section{Materials and Methods}

\section{Patients}

Bone marrow or peripheral blood samples were obtained between 1989 and 2009 from 25 
patients with newly diagnosed APL. All cases were confirmed to harbor $\mathrm{t}(15 ; 17)$ by means of karyotyping or FISH and the PML-RAR $\alpha$ fusion transcript by RT-PCR. ${ }^{20}$ Diagnostic slides were morphologically classified into hypergranular (M3) and micro/hypogranular variant (M3v) forms on the basis of standard FAB criteria. ${ }^{21}$ All samples showing high levels of blast cells and high-quality RNA were selected for gene expression analysis.

\section{Immunophenotypic analysis}

Immunophenotypic analysis was performed with FACSCalibur (Becton Dickinson, San José, CA, USA), using commercially available reagents. The panel of phycoerythrin (PE)- or fluorescein isothiocyanate (FITC)-conjugated monoclonal antibodies against: i) myeloid lineage-associated antigens, CD11b, CD13, CD14, CD15 and CD33; ii lymphoid lineage-associated antigens CD2, CD3, CD7, CD10, CD19, CD22 and CD79; and iii) lineage non-specific antigens HLA-DR, CD34, CD45 and CD56, were used to analyze the leukemic cells of patients. Expression in more than $20 \%$ of leukemic cells was set as the positivity cut-off level for a given antigen, with the exception of CD34 for which this was set at $10 \%{ }^{3}$

\section{Reverse transcription-polymerase chain reaction for the PML-RAR $\alpha$ fusion transcript and terminal deoxynucleotidyl transferase mRNA}

Total RNA was isolated with the RNeasy Mini kit (Qiagen GmbH, Hilden, Germany) and cDNA was constructed from $1 \mu \mathrm{g}$ of total RNA with the First Strand cDNA Synthesis kit for RT-PCR (AMV) (Roche Diagnostics, Tokyo, Japan) according to the manufacturers' instructions. For the PML-RAR $\alpha$ fusion transcript, cDNA was amplified with two-step nested PCR in $2 \mathrm{mM} \mathrm{MgCl}_{2}, 200 \mathrm{mM}$ dNTP, GeneAmp 10X PCR Gold Buffer containing 15 $\mathrm{mM}$ Tris-HCL (pH 8.0) and $50 \mathrm{mM} \mathrm{KCl}$, and 1.25 U AmpliTaq Gold (Applied Biosystems, Foster City, CA, USA), using $0.2 \mu \mathrm{M}$ each of primer P1, 5'-ATGCTGTGCTGCAGCGCAT-3' and R7, 5'-CCATAGTGGTAGCCTGAGGAC-3'. After 10 min of incubation at $95^{\circ} \mathrm{C}$, PCR was performed at 35 cycles of $95^{\circ} \mathrm{C}$ for $30 \mathrm{~s}, 60^{\circ} \mathrm{C}$ for $30 \mathrm{~s}$, and $72^{\circ} \mathrm{C}$ for $30 \mathrm{~s}$. From $50 \mu \mathrm{L}$ of the product obtained with the first step, $5 \mu \mathrm{L}$ was amplified with the nested primers P2, 5'-
CAGAGGATGAAGTGCTACG-3' and R9, 5'-GTCCTGACAGACAAAGCAAG-3' under the same conditions as for the first step PCR. All 25 APL patients were analyzed for classification of the specific PML-RAR $\alpha$ isoforms bcrl (long), bcr2 (variable), and bcr3 (short). The PML-RAR $\alpha$ transcript for each patient was also measured by the real-time quantitative PCR (RQ-PCR) method that we recently established. ${ }^{22}$ PCR for TdT detection was performed as previously described. ${ }^{23}$

\section{Detection of the FLT3 mutations}

cDNA was examined for the detection of FLT3/ITD. Exons 14 and 15 covering the JM domain were amplified, using the specific primers $\mathrm{R} 5$ and $12 \mathrm{R}$ as described by Kiyoi et $a l .{ }^{24}$ FLT3/ITD was detected as an additional longer PCR product by 3\% agarose gel electrophoresis, and purified PCR products were sequenced with the $\mathrm{ABI} 3130 \mathrm{xl}$ DNA sequencer (Applied Biosystems) after being ligated to a TA cloning vector (Invitrogen, Carlsbad, CA, USA). To detect D835 and I836 mutations, exon 20, which corresponds to TKD2, was amplified with the primers $17 \mathrm{~F}$ and $17 \mathrm{R}$ as described by Yamamoto et al. ${ }^{25}$ D835 and I836 amino acids

Table 1. Clinical characteristics of 25 acute myeloid leukemia patients with PML/RAR $\alpha$ mRNA.

\begin{tabular}{|c|c|c|c|c|c|c|c|c|}
\hline Case & Age/sex & Morphology & PML/RAR $\alpha$ isoform & $\mathrm{CD} 2$ & $\begin{array}{l}\text { Sur } \\
\text { CD34 }\end{array}$ & $\begin{array}{l}\text { rkers } \\
\text { CD56 }\end{array}$ & HLA-DR & TdTmRNA \\
\hline 1 & $50 \mathrm{M}$ & M3 & Long/bcrl & - & - & - & - & - \\
\hline 2 & $41 \mathrm{~F}$ & M3 & Short/bcr3 & + & + & - & - & - \\
\hline 3 & $6 \mathrm{~F}$ & M3 & Short/bcr3 & - & - & - & - & - \\
\hline 4 & $51 \mathrm{~F}$ & M3 & Long/bcrl & - & - & - & - & - \\
\hline 5 & $60 \mathrm{~F}$ & M3 & Long/bcrl & - & - & - & - & - \\
\hline 6 & $44 \mathrm{M}$ & M3 & Variable/bcr2 & + & - & - & - & - \\
\hline 7 & $16 \mathrm{M}$ & M3 & Short/bcr3 & + & - & - & + & - \\
\hline 8 & $29 \mathrm{~F}$ & M3 v & Short/bcr3 & + & + & + & - & + \\
\hline 9 & $44 \mathrm{~F}$ & M3 & Variable/bcr2 & - & - & - & - & - \\
\hline 10 & $64 \mathrm{~F}$ & M3 & Long/bcrl & - & - & - & - & - \\
\hline 11 & $72 \mathrm{M}$ & M3 v & Short/bcr3 & + & - & - & - & - \\
\hline 12 & $64 \mathrm{~F}$ & M3 & Long/bcrl & + & - & - & - & + \\
\hline 13 & $52 \mathrm{~F}$ & M3 v & Short/bcr3 & + & + & - & - & + \\
\hline 14 & $65 \mathrm{M}$ & M3 & Short/bcr3 & - & + & - & - & + \\
\hline 15 & $14 \mathrm{M}$ & M3 v & Short/bcr3 & + & + & - & - & + \\
\hline 16 & $24 \mathrm{M}$ & M3 & Long/bcrl & - & - & - & - & - \\
\hline 17 & $10 \mathrm{~F}$ & M3 & Long/bcr1 & - & - & - & - & - \\
\hline 18 & $26 \mathrm{M}$ & M3 v & Short/bcr3 & + & + & - & - & + \\
\hline 19 & $70 \mathrm{M}$ & M3 & Long/bcr1 & + & - & + & - & - \\
\hline 20 & $61 \mathrm{~F}$ & M3 & Long/bcrl & - & - & - & - & - \\
\hline 21 & $45 \mathrm{M}$ & M3 & Short/bcr3 & - & - & - & - & - \\
\hline 22 & $20 \mathrm{~F}$ & M3 & Long/bcrl & - & + & + & + & - \\
\hline 23 & $54 \mathrm{M}$ & M3 & Long/bcrl & - & - & + & - & - \\
\hline 24 & $61 \mathrm{~F}$ & M3 & Long/bcrl & - & + & - & - & + \\
\hline 25 & $13 \mathrm{M}$ & M3 & Long/bcrl & - & - & - & - & - \\
\hline
\end{tabular}


were encoded using GATATC, which is the recognition site for EcoRV. After PCR, amplified products were digested with EcoRV (Takara, Kyoto, Japan) at $37^{\circ} \mathrm{C}$ for $3 \mathrm{~h}$ and subjected to electrophoresis on a $4 \%$ agarose gel. Digested products were then separated into two bands, and products that were undigested, thus indicating the presence of D835 or I836 mutations, were detected as a single band, which was confirmed by sequencing as described above.

\section{Quantification of the FLT3 transcript by real-time polymerase chain reaction}

cDNA was synthesized from each RNA sample as described above. Real-time PCR using the ABI Prism 7700 sequence detection system (Applied Biosystems) was performed to quantify the FLT3 transcript in 25 samples. Sequences of sense and antisense primers and the TaqMan ${ }^{\circledR}$ probe, as well as PCR conditions, were described by Ozeki et al. ${ }^{26}$ For the housekeeping gene, GAPDH, human GAPDH (x20) (Applied Biosystems) was used. A standard curve was produced for FLT3 and GAPDH by means of a 10 -fold dilution of six different plasmid concentrations. The gene expression level of the FLT3 transcript in each of the samples was normalized relative to the level of the GAPDH transcript.

\section{Statistical analysis}

Student's unpaired t-test was used for statistical comparisons between groups. Welch's unpaired t-test was also used to verify evaluations of the significance of differences between 2 groups with different variances. All $P$ values were two-tailed; $\mathrm{P}<0.05$ was considered significant.
Table 2. FLT3 mutation status of 25 acute myeloid leukemia patients with PML/RAR $\alpha$ mRNA.

\begin{tabular}{|c|c|c|c|c|}
\hline \multirow[t]{2}{*}{ Case } & \multicolumn{2}{|c|}{ FLT3/ITD } & \multirow{2}{*}{$\begin{array}{c}\text { D835Mt } \\
\text { Substitution }\end{array}$} & \multirow{2}{*}{$\begin{array}{l}\text { FLT3mRNA } \\
\text { (/GAPDH) }\end{array}$} \\
\hline & Location (nt range)* & Length (bp) & & \\
\hline 1 & & & & 0.048 \\
\hline 2 & 1829-1885 & 57 & & 0.068 \\
\hline 3 & & & & 0.066 \\
\hline 4 & & & Tyr & 0.179 \\
\hline 5 & & & & 0.165 \\
\hline 6 & 1832-1864 & 33 & & 0.853 \\
\hline 7 & $1805-1852$ & 48 & & 0.101 \\
\hline 8 & $1805-1852$ & 48 & His & 0.314 \\
\hline 9 & & & Ile836Phe $^{\circ}$ & 0.028 \\
\hline 10 & & & & 0.061 \\
\hline 11 & 1832-1864 & 33 & & 0.782 \\
\hline 12 & & & & 0.073 \\
\hline 13 & 1841-1861 & 21 & Tyr & 0.274 \\
\hline 14 & & & Glu & 0.270 \\
\hline 15 & $1800-1855$ & $56+1$ & & 0.438 \\
\hline 16 & & & Tyr & 0.031 \\
\hline 17 & & & & 0.155 \\
\hline 18 & 1829-1885 & 57 & & 0.291 \\
\hline 19 & 1841-1861 & 21 & & 0.496 \\
\hline 20 & & & Val & 0.018 \\
\hline 21 & & & His & 0.584 \\
\hline 22 & & & & 0.076 \\
\hline 23 & $\otimes \gamma$ & & & 0.279 \\
\hline 24 & 8 & & & 0.005 \\
\hline 25 & $9(3)$ & & His & 0.128 \\
\hline
\end{tabular}

*nt, nucleotide; ${ }^{\circ}$ the amino acid lle of 1836 was replaced with Phe.

Table 3. Relationship between FLT3 mutation status and disease characteristics.

\begin{tabular}{|c|c|c|c|c|c|c|c|}
\hline & Total (\%) & $+(\%)$ & $\begin{array}{c}\text { ITD } \\
-(\%)\end{array}$ & $\mathbf{P}$ & $+(\%)$ & $\begin{array}{c}\text { D835Mt } \\
-(\%)\end{array}$ & $\mathbf{P}$ \\
\hline Patients & 25 & $9(36.0)$ & $16(64.0)$ & & $9(36.0)$ & $16(64.0)$ & \\
\hline FAB subtype & & & & $<0.001$ & & & 0.835 \\
\hline M3 & $20(80.0)$ & $4(44.4)$ & $16(100.0)$ & & $7(77.8)$ & $13(81.3)$ & \\
\hline M3v & $5(20.0)$ & $5(55.6)$ & $0(0)$ & & $2(22.2)$ & $3(18.8)$ & \\
\hline $\mathrm{PML} / \mathrm{RAR} \alpha$ isoform & & & & 0.008 & & & 0.821 \\
\hline Long/bcrl & $13(52.0)$ & $1(11.1)$ & $12(75.0)$ & & $4(44.4)$ & $9(56.3)$ & \\
\hline Short/bcr3 & $10(40.0)$ & $7(77.8)$ & $3(18.8)$ & & $4(44.4)$ & $6(37.5)$ & \\
\hline Variable/bcr2 & $2(8.0)$ & $1(11.1)$ & $1(6.3)$ & & $1(11.1)$ & $1(6.3)$ & \\
\hline \multicolumn{8}{|l|}{ Surface markers } \\
\hline $\mathrm{CD} 2+$ & $10(40.0)$ & $9(100.0)$ & $1(6.3)$ & $<0.001$ & $2(22.2)$ & $8(50.0)$ & 0.174 \\
\hline CD34 + & $8(32.0)$ & $5(55.6)$ & $3(18.8)$ & 0.058 & $3(33.3)$ & $5(31.3)$ & 0.915 \\
\hline CD56 + & $4(16.0)$ & $2(22.2)$ & $2(12.5)$ & 0.525 & $1(11.1)$ & $3(18.8)$ & 0.617 \\
\hline $\mathrm{CD} 2+34+$ & $5(20.0)$ & $5(55.6)$ & $0(0)$ & $<0.001$ & $2(22.2)$ & $3(18.8)$ & 0.835 \\
\hline $\mathrm{CD} 2+56+$ & $2(8.0)$ & $2(22.2)$ & $0(0)$ & 0.049 & $1(11.1)$ & $1(6.3)$ & 0.667 \\
\hline CD34+56 + & $2(8.0)$ & $1(11.1)$ & $1(6.3)$ & 0.667 & $1(11.1)$ & $1(6.3)$ & 0.667 \\
\hline $\mathrm{CD} 2+34+56+$ & $1(4.0)$ & $1(11.1)$ & $0(0)$ & 0.174 & $1(11.1)$ & $0(0)$ & 0.174 \\
\hline CD2or34or56+ ${ }^{\mathrm{a}}$ & $14(56.0)$ & $9(100.0)$ & $5(31.3)$ & $<0.001$ & $3(33.3)$ & $11(68.8)$ & 0.087 \\
\hline $\mathrm{TdT}+$ & $7(28)$ & $4(44.4)$ & $3(18.8)$ & 0.170 & $3(33.3)$ & $4(25.0)$ & 0.656 \\
\hline
\end{tabular}

Mean values (minimum to maximum) for FLT3 mRNA. P values were determined with the t test for surface markers, TdT, and FLT3mRNA, and with Fisher's exact test for PML/RAR $\alpha$ isoform. *Incidence of at least one of the three surface markers. 


\section{Results}

Relationships between morphology, the PML-RAR $\alpha$ isoform, and aberrant surface antigens

Morphology, the PML-RAR $\alpha$ isoform, and results for aberrant surface antigens of the 25 APL patients are shown in Table 1. The short/bcr3 isoform was detected more frequently in M3v cases (5 of 5) than in hypergranular M3 cases (5 of 20) ( $\mathrm{P}=0.009)$. All 25 cases were positive for CD13 and CD33 (data not shown) and 2 of 25 cases (8\%) were positive for HLA-DR. T-cell associated antigen CD2, the hematopoietic stem cell antigen CD34, as well as their combined expression, occurred significantly more frequently in the short/bcr3 $(\mathrm{P}=0.008,0.026$ and 0.004 , respectively) than that in the long/bcrl isoform, and in $\mathrm{M} 3 \mathrm{v}$ $(\mathrm{P}=0.002,0.010$ and $<0.001$, respectively) than in hypergranular M3. The frequency of CD2, CD34, and their co-expression was also significantly higher in $\mathrm{TdT} \mathrm{mRNA}^{+}$cases than that in TdT mRNA ${ }^{-}$cases $(\mathrm{P}=0.046,<0.001$ and 0.004 , respectively).

\section{Detection of FLT3 mutations}

Alterations in the FLT3 gene were detected by direct sequencing of PCR products for the PML-RAR $\alpha$ transcript. Results for all 25 patients with PML-RAR $\alpha$ mRNA are listed in Table 2. FLT3/ITD and FLT3/D835 (I836) were found in 9 patients each (36\%). The size of duplicated FLT3/ITD fragments varied from $21 \mathrm{bp}$ to $57 \mathrm{bp}$, and the reading frame was always maintained. One case (n. 15) harbored tandem duplications plus insertion sequences between duplications. Sequencing analysis also showed that there were 8 cases with D835 mutations, but all were missense, resulting in the substitution of Asp for Tyr (D835Y), His (D835H), Glu (D835E), or Val (D835V). One case (n. 9) possessed a three-base pair (GAT) deletion together with a missense mutation at codon 836 , resulting in the substitution of Ile for Phe. Two cases (ns. 8 and 13) showed both FLT3/ITD and FLT3/D835.

\section{Association between FLT3 mutation status and the PML- RAR $\alpha$ isoform or surface markers}

As shown in Table 3, the presence of ITD correlated significantly with M3v morphology $(\mathrm{P}<0.001)$ and the short/bcr3 PML breakpoint $(\mathrm{P}=0.008)$, but no correlation was observed with the presence of D835/836 mutations. Expression of CD2 was found in all FLT3/TD ${ }^{+}$ cases $(9$ of 9$)$. The frequency of FLT3/TD ${ }^{+}$ occurrence was significantly higher in $\mathrm{CD} 2^{+}$ cases than in $\mathrm{CD}^{-}$- cases $(\mathrm{P}<0.001)$, with only one case among the former (n. 12) not harboring FLT3/TD (1 of 10, 10\%). Furthermore, all $\mathrm{CD}^{+}{ }^{+} \mathrm{CD} 34^{+}$cases possessed FLT3/TTD (5 of 5 , $\mathrm{P}<0.001)$. In contrast, there were no correlations between the presence of D835/1836 mutations and that of aberrant surface-antigens, such as CD2, CD34 and CD56. The absence of aberrant surface-antigens was confirmed in 6 of the 9 cases with D835/I836+ (66.7\%), and 2 of the 3 cases expressing aberrant surfaceantigens showed both FLT3/ITD and D835 mutations (case ns. 8 and 13). Expression of CD56 or TdT mRNA was not associated with either FLT3/ITD ( $\mathrm{P}=0.525,0.170$, respectively) or $\mathrm{D} 835 / 1836(\mathrm{P}=0.617,0.656$, respectively $)$ mutations.

\section{Expression levels of the $F L T 3$ transcript}

We quantified the expression levels of the FLT3 transcript in all patients by means of realtime PCR (Table 2). The mean expression level was 0.231 (/GAPDH mRNA), ranging from 0.018 to 0.853 . For controls based on normal hematopoietic cells, we also quantified expression levels of 19 normal PB MNCs, with a mean expression of 0.015 (/GAPDH mRNA), ranging from 0.010 to 0.032 (data not shown). Table 4 shows that the expression levels of FLT3 mRNA were significantly higher in FLT3/ITD+ than in FLT3/ITD $^{-}$cases (median 0.402 vs 0.135 , $\mathrm{P}=0.025$ ), whereas there was no significant difference in those between D835/I836 ${ }^{+}$and D835/I836- cases (median 0.203 vs 0.247 , $\mathrm{P}=0.660$ ). Overall, cases with FLT3 mutations, whether ITD or D835, showed significantly higher levels of FLT3 mRNA than those without mutations (median 0.303 vs $0.103, \mathrm{P}=0.012$ ). $\mathrm{CD}^{+}$cases had higher levels of FLT3 mRNA than those of $\mathrm{CD}^{-}$cases (median $0.369 \mathrm{vs}$ $0.140, \mathrm{P}=0.038$ ), as did cases with the bcr3 PML breakpoint cases relative to bcrl cases (median 0.319 vs $0.132, \mathrm{P}=0.024$ ).

\section{Discussion}

APL is characterized by the expression of cell surface antigens, such as $\mathrm{CD} 13^{+}, \mathrm{CD}^{2} 3^{+}$, HLA-DR ${ }^{-}, \mathrm{CD}_{14}{ }^{-}$, and $\mathrm{CD}^{-}{ }^{-3,4,9}$ However, different studies have reported that the frequency of CD34+ in APL was found to range from 20$31 \% .3,27-30$ Our study detected a frequency of $32 \%$ (8 of 25), thus confirming previously reported values. The significance of $\mathrm{CD} 34$ expression is not yet known, but it is likely to indicate an immature form of APL. ${ }^{3,31}$ In addition, T-cell associated antigen CD2 has been reported to possess features such as M3v morphology and the bcr3 isoform and to have a poorer prognosis than CD2- APL cases. ${ }^{27,28,30,32}$ In our study, CD2, CD34, and their combined expression were detected significantly more frequently in their bcr3 isoform than that in their bcrl form $(\mathrm{P}=0.008,0.026$ and 0.004 , respectively), and in $\mathrm{M} 3 \mathrm{v}$ than in classical hypergranular $\mathrm{M} 3(\mathrm{P}=0.002,0.010$ and $<0.001$, respectively) (data not shown). These results are in agreement with those of other studies, 
which reported that CD2, CD34, and their combined expression were associated with the immature phenotypic characteristics of APL. ${ }^{31,33}$ In this study, all FLT3/ITD ${ }^{+}$cases showed CD2 (9 of 9) expression, and all but one of the $\mathrm{CD}^{+}$cases harbored FLT3/ITD (1 of $10,10 \%)$, indicating that the presence of ITD showed a significant correlation with CD2 expression. Our study describes the relationship between the presence of FLT3/ITD and immunophenotypic expressions, including the expression of CD2 and CD34, while it has also been reported that the presence of ITD is associated with M3v morphology and the short/bcr3 PML breakpoint in a large series of APL patients. ${ }^{19,34}$ We also found that all patients with co-expression of CD2 and CD34 harbored FLT3/ITD ${ }^{+}$(5 of $5, \mathrm{P}<0.001$ ). While several reports on FLT3 published so far have focused on WBC count, morphology, and cytogenesis in APL, ${ }^{18,19,24}$ we demonstrated that FLT3/ITD is closely associated with immature immunophenotypic expressions, such as those of CD2 and CD34. Considering that 10 (40\%) of the 25 APL patients enrolled in our study expressed cellsurface antigen CD2, it is of interest that CD2 expression was closely associated with M3v morphology and the expression of the stem cell marker CD34, while few patients with classical M3 morphology expressed these surface markers. The mechanism leading to aberrant expression of lymphoid markers in AML remains unclear. According to the lineage infidelity model, ${ }^{35}$ this phenomenon is a result of the deregulation of lineage-affiliated genes occurring during the process of leukemic transformation. However, according to the lineage promiscuity model, ${ }^{36}$ co-expression of myeloid and lymphoid markers reflects the immunophenotype of the progenitor population subjected to leukemic transformation, such that $\mathrm{CD} 2+\mathrm{CD} 34^{+}$cases may develop from the most primitive precursors. Grignani et al. reported that one of the effects of deregulation on the PML-RAR $\alpha$ fusion protein was the rapid differentiation induction of hematopoietic progenitor cells or hematopoietic stem cells to the promyelocytic stage, followed by maturation arrest. $^{37}$ This raises the possibility that the presence of FLT3/ITD, which correlates strongly with the expression of CD2 and CD34, could contribute to blocking the differentiation of leukemic blasts at a more immature stage than the promyelocytic stage. We, therefore, suggest that FLT3/ITD is one of the additional molecular mutations that cause cells to remain as an immature phenotype in APL positive for PML-RAR $\alpha$ mRNA.

Our quantitative data demonstrated that FLT3 mRNA levels were significantly higher in FLT3/ITD $^{+}$cases than those in FLT3/ITDcases, whereas there were no significant differences between those with or without
FLT3/D835 (I836). Our findings for FLT3/D835 were inconsistent with the findings reported by Ozeki et al. ${ }^{26}$ in which FLT3 mRNA levels were significantly higher in AML cases with FLT3/D835 as well as with FLT3/ITD than in those without mutations. This discrepancy may be attributed to the higher percentage of D835 positive cases (36\%) in our study. Furthermore, $\mathrm{CD} 2^{+}$cases also showed significantly higher FLT3 mRNA levels than those of CD2- cases. Results of the immunophenotypic analysis of our quantitative data, which indicate that FLT3/ITD, not FLT3/D835, is closely associated with high expression levels of FLT3 mRNA, suggest that the presence of an ITD could represent a distinct molecular entity of the disease. Several studies have reported clinical outcomes specifically for patients with AML who harbor FLT3 mutations. Some studies found no significant differences in diseasefree survival between patients with and without FLT3/ITD, ${ }^{24,38,39}$ whereas others reported a tendency toward shorter overall survival and significantly worse disease-free survival for patients with FLT3/ITD. ${ }^{19,40}$ In contrast, most studies examining the presence of FLT3/TKD point mutations alone in the absence of an ITD have found no significant impact of its presence on clinical outcome for AML. ${ }^{14,25,34,41}$ It is of further interest that these authors suggest that differences in clinical outcome between the two events, ITD and TKD point mutations, appear to have the same functional result, i.e. loss of autoinhibitory regulation leading to constitutive FLT3 kinase activation, ${ }^{42}$ and one reason for this may be that the signaling properties of activation loop (TKD) mutations differ from those of ITD-carrying receptors. ${ }^{41}$ Microarray analysis has also disclosed differences in expression profiles among patients with FLT3/ITD, D835/I836, and wild-type FLT3. ${ }^{43}$ Our data clarified differences between the two events by showing the expression of aberrant surface markers and expression levels of the FLT3 transcript. Two recent largescale studies of APL found no evidence of any differences between APL and non-APL patients regarding the influence of FLT3/ITD status on clinical outcome, and confirmed that the presence of FLT3/ITD was related to very poor postrelapse survival. ${ }^{19,43}$ This suggests that FLT3/ITD ${ }^{+}$patients are characterized by an underlying genetic instability which leads to the acquisition of some additional, as yet unknown, gene mutation at relapse which carries with it a bad prognosis. ${ }^{19}$

\section{Conclusions}

In conclusion, we showed that the presence of FLT3/ITD, but not D835 (I836), is closely related to an immature immunophenotype in APL. This is the first reported study to demonstrate that an additional genetic event is closely associated with the cell surface antigen in APL. Our findings, obtained with molecular and immunophenotypic analysis, which appear to be the most valuable tools for identifying previously unrecognized variant morphologies, raise the possibility that the presence of FLT3/ITD and the expression of CD2 differentiate a subset of APL patients with different biological characteristics. Although we did not evaluate the clinical course or prognosis for APL patients in our study, our findings can be expected to contribute to the clarification of a role for FLT3/ITD in the pathogenesis of APL. Further large-scale studies of APL patients are needed to determine whether the presence of FLT3/ITD and the expression of CD2 constitute independent clinical factors.

\section{References}

1. Melnick A, Licht JD. Deconstructing a disease: RARalpha, its fusion partners, and their roles in the pathogenesis of acute promyelocytic leukemia. Blood 1999;93: 3167-215.

2. Rowley JD, Golomb HM, Dougherty C. 15/17 translocation, a consistent chromosomal change in acute promyelocytic leukaemia. Lancet 1977;1:549-50.

3. Guglielmi C, Martelli MP, Diverio D, et al. Immunophenotype of adult and childhood acute promyelocytic leukaemia: correlation with morphology, type of PML gene breakpoint and clinical outcome. A cooperative Italian study on 196 cases. Br J Haematol 1998;102:1035-41.

4. Neame PB, Soamboonsrup P, Leber B, et al. Morphology of acute promyelocytic leukemia with cytogenetic or molecular evidence for the diagnosis: characterization of additional microgranular variants. Am J Hematol 1997;56:131-42.

5. Rovelli A, Biondi A, Cantu Rajnoldi A, et al. Microgranular variant of acute promyelocytic leukemia in children. J Clin Oncol 1992;10:1413-8.

6. Biondi A, Luciano A, Bassan R, et al. CD2 expression in acute promyelocytic leukemia is associated with microgranular morphology (FAB M3v) but not with any PML gene breakpoint. Leukemia 1995; 9:1461-6.

7. Claxton DF, Reading CL, Nagarajan L, et al. Correlation of CD2 expression with PML gene breakpoints in patients with acute promyelocytic leukemia. Blood 1992;80: 582-6.

8. Ferrara F, Morabito F, Martino B, et al. CD56 expression is an indicator of poor 
clinical outcome in patients with acute promyelocytic leukemia treated with simultaneous all-trans-retinoic acid and chemotherapy. J Clin Oncol 2000;18:1295300.

9. Paietta E, Andersen J, Gallagher R, et al. The immunophenotype of acute promyelocytic leukemia (APL): an ECOG study. Leukemia 1994;8:1108-12.

10. Small D, Levenstein M, Kim E, et al. STK-1, the human homolog of Flk-2/Flt-3, is selectively expressed in CD34+ human bone marrow cells and is involved in the proliferation of early progenitor/stem cells. Proc Natl Acad Sci USA 1994;91:459-63.

11. Brown P, Small D. FLT3 inhibitors: a paradigm for the development of targeted therapeutics for paediatric cancer. Eur J Cancer 2004;40:707-21.

12. Kottaridis PD, Gale RE, Frew ME, et al. The presence of a FLT3 internal tandem duplication in patients with acute myeloid leukemia (AML) adds important prognostic information to cytogenetic risk group and response to the first cycle of chemotherapy: analysis of 854 patients from the United Kingdom Medical Research Council AML 10 and 12 trials. Blood 2001;98:1752-9.

13. Thiede C, Steudel C, Mohr B, et al. Analysis of FLT3-activating mutations in 979 patients with acute myelogenous leukemia: association with FAB subtypes and identification of subgroups with poor prognosis. Blood 2002;99:4326-35.

14. Frohling S, Schlenk RF, Breitruck J, et al. Prognostic significance of activating FLT3 mutations in younger adults (16 to 60 years) with acute myeloid leukemia and normal cytogenetics: a study of the AML Study Group Ulm. Blood 2002;100:4372-80.

15. Iwai T, Yokota S, Nakao M, et al. Internal tandem duplication of the FLT3 gene and clinical evaluation in childhood acute myeloid leukemia. The Children's Cancer and Leukemia Study Group, Japan. Leukemia 1999;13:38-43.

16. Meshinchi S, Woods WG, Stirewalt DL, et al. Prevalence and prognostic significance of Flt3 internal tandem duplication in pediatric acute myeloid leukemia. Blood 2001;97:89-94.

17. Shih LY, Kuo MC, Liang DC, et al. Internal tandem duplication and Asp835 mutations of the FMS-like tyrosine kinase 3 (FLT3) gene in acute promyelocytic leukemia. Cancer 2003;98:1206-16.

18. Schnittger S, Schoch C, Dugas M, et al. Analysis of FLT3 length mutations in 1003 patients with acute myeloid leukemia: correlation to cytogenetics, FAB subtype, and prognosis in the AMLCG study and usefulness as a marker for the detection of minimal residual disease. Blood 2002;100:59-66.

19. Callens C, Chevret S, Cayuela JM, et al.
Prognostic implication of FLT3 and Ras gene mutations in patients with acute promyelocytic leukemia (APL): a retrospective study from the European APL Group. Leukemia 2005;19:1153-60.

20. Borrow J, Goddard AD, Gibbons B, et al. Diagnosis of acute promyelocytic leukaemia by RT-PCR: detection of PMLRARA and RARA-PML fusion transcripts. $\mathrm{Br}$ J Haematol 1992;82:529-40.

21. Bennett JM, Catovsky D, Daniel MT, et al. Proposed revised criteria for the classification of acute myeloid leukemia. A report of the French-American-British Cooperative Group. Ann Intern Med 1985;103:620-5.

22. Takenokuchi M, Nakamachi Y, Yoneda K, et al. Quantitative detection of PMLRARalpha fusion transcript by real-time PCR with a single primer pair. J Clin Lab Anal 2009;23:223-30.

23. Hardianti MS, Tatsumi E, Syampurnawati $\mathrm{M}$, et al. Presence of somatic hypermutation and activation-induced cytidine deaminase in acute lymphoblastic leukemia L2 with $\mathrm{t}(14 ; 18)(\mathrm{q} 32 ; \mathrm{q} 21)$. Eur J Haematol 2005;74:11-9.

24. Kiyoi H, Naoe T, Yokota S, et al. Internal tandem duplication of FLT3 associated with leukocytosis in acute promyelocytic leukemia. Leukemia Study Group of the Ministry of Health and Welfare (Kohseisho). Leukemia 1997;11:1447-52.

25. Yamamoto Y, Kiyoi H, Nakano Y, et al. Activating mutation of D835 within the activation loop of FLT3 in human hematologic malignancies. Blood 2001;97:2434-9.

26. Ozeki K, Kiyoi H, Hirose Y, et al. Biologic and clinical significance of the FLT3 transcript level in acute myeloid leukemia. Blood 2004;103:1901-8.

27. Foley R, Soamboonsrup P, Carter RF, et al. CD34-positive acute promyelocytic leukemia is associated with leukocytosis, microgranular/hypogranular morphology, expression of CD2 and bcr3 isoform. Am J Hematol 2001;67:34-41.

28. Paietta E, Goloubeva O, Neuberg D, et al. A surrogate marker profile for PML/RAR alpha expressing acute promyelocytic leukemia and the association of immunophenotypic markers with morphologic and molecular subtypes. Cytometry B Clin Cytom 2004;59:1-9.

29. Lee JJ, Cho D, Chung IJ, et al. CD34 expression is associated with poor clinical outcome in patients with acute promyelocytic leukemia. Am J Hematol 2003;73:14953.

30. Lin P, Hao S, Medeiros LJ, et al. Expression of CD2 in acute promyelocytic leukemia correlates with short form of PMLRARalpha transcripts and poorer prognosis. Am J Clin Pathol 2004;121:402-7.

31. Albano F, Mestice A, Pannunzio A, et al. The biological characteristics of CD34+ CD2+ adult acute promyelocytic leukemia and the CD34 CD2 hypergranular (M3) and microgranular (M3v) phenotypes. Haematologica 2006;91:311-6.

32. Grimwade D, Outram SV, Flora R, et al. The T-lineage-affiliated CD2 gene lies within an open chromatin environment in acute promyelocytic leukemia cells. Cancer Res 2002;62:4730-5.

33. Montesinos P, Rayon C, Vellenga E, et al. Clinical significance of CD56 expression in patients with acute promyelocytic leukemia treated with all-trans retinoic acid and anthracycline-based regimens. Blood 2011;117:1799-805.

34. Barragan E, Montesinos P, Camos M, et al. Prognostic value of FLT3 mutations in patients with acute promyelocytic leukemia treated with all-trans retinoic acid and anthracycline monochemotherapy. Haematologica 2011;96:1470-7.

35. Smith LJ, Curtis JE, Messner HA, et al. Lineage infidelity in acute leukemia. Blood 1983;61:1138-45.

36. Greaves MF, Chan LC, Furley AJ, et al. Lineage promiscuity in hemopoietic differentiation and leukemia. Blood 1986;67:111.

37. Grignani F, Valtieri M, Gabbianelli M, et al. PML/RAR alpha fusion protein expression in normal human hematopoietic progenitors dictates myeloid commitment and the promyelocytic phenotype. Blood 2000; 96:1531-7.

38. Shih LY, Huang CF, Wu JH, et al. Internal tandem duplication of FLT3 in relapsed acute myeloid leukemia: a comparative analysis of bone marrow samples from 108 adult patients at diagnosis and relapse. Blood 2002;100:2387-92.

39. Noguera NI, Breccia M, Divona M, et al. Alterations of the FLT3 gene in acute promyelocytic leukemia: association with diagnostic characteristics and analysis of clinical outcome in patients treated with the Italian AIDA protocol. Leukemia 2002;16:2185-9.

40. Au WY, Fung A, Chim CS, et al. FLT-3 aberrations in acute promyelocytic leukaemia: clinicopathological associations and prognostic impact. Br J Haematol 2004;125: 463-9.

41. Abu-Duhier FM, Goodeve AC, Wilson GA, et al. Identification of novel FLT-3 Asp835 mutations in adult acute myeloid leukaemia. Br J Haematol 2001;113:983-8.

42. Levis M, Small D. FLT3: ITDoes matter in leukemia. Leukemia 2003;17:1738-52.

43. Gale RE, Hills R, Pizzey AR, et al. Relationship between FLT3 mutation status, biologic characteristics, and response to targeted therapy in acute promyelocytic leukemia. Blood 2005;106:3768-76. 